\title{
The newer Opioid Agonist Treatment with lower substitutive opiate doses is associated with better toxicology outcome than the older Harm Reduction Treatment
}

Jacopo V. Bizzarri ${ }^{1}$, Valentina Casetti ${ }^{1}$, Livia Sanna ${ }^{1}$, Angelo Giovanni Icro Maremmani ${ }^{2,3}$, Luca Rovai ${ }^{2}$, Silvia Bacciardi ${ }^{2}$, Daria Piacentino ${ }^{1}$, Andreas Conca ${ }^{1}$ and Icro Maremmani ${ }^{2,3,4^{*}}$

\begin{abstract}
Background: Charge-free heroin use disorder treatment in Italy follows two main approaches, i.e., harm reduction treatment (HRT) strategy in community low-threshold facilities for drug addiction and opioid agonist treatment (OAT) in high-threshold facilities for opioid addiction, focusing on pharmacological maintenance according to the Dole and Nyswander strategy. We aimed to compare the impact of HRT and OAT on patient outcome, as assessed through negativity for drugs on about 1-year urinalyses.

Methods: We examined retrospectively the urinalyses of HRT and OAT patients for which at least four randomly sampled urinalyses per month were available for about 1 year, during which patients were undergoing methadone or buprenorphine maintenance; urinalyses focused on heroin, cocaine, cannabinoids, and their metabolites.

Results: Included were 189 HRT and 58 OAT patients. The latter were observed for a significantly longer period. There was a higher proportion of heroin- and cocaine-clean urinalyses in OAT patients, with cocaine-clean urinalyses discriminating best between the two groups. OAT patients were older, with longer dependence duration, more severe addiction history, and received lower methadone doses. Buprenorphine maintenance was more often associated with heroin-clean urinalyses. The higher the methadone doses, the lower were the percentage of heroin-clean urinalyses in HRT patients (negative correlation).

Conclusions: The OAT approach was related to higher recovery and polyabuse abstinence rates compared to the HRT approach, despite greater severity of substance use, psychiatric and physical comorbidities. Our results are consistent with the possibility to use lower maintenance opiate doses (after induction and stabilization in methadone treatment according to Dole and Nyswander methodology) in treating heroin addiction. This seemed to be impossible adopting the currently accepted HRT model.
\end{abstract}

Keywords: Harm reduction treatment, Agonist opioid treatment, Urinalyses, Polysubstance use, Heroin, Cannabinoids, Cocaine

\footnotetext{
*Correspondence: icro.maremman@med.unipi.i

${ }^{2}$ Vincent P. Dole Dual Diagnosis Unit, Department of Neurosciences,

Santa Chiara University Hospital, University of Pisa, Via Roma, 67

56100 Pisa, Italy

Full list of author information is available at the end of the article
} 


\section{Background}

Opioid misuse is a long-term and often chronic condition [1] that has an estimated prevalence of $0.40 \%$ in the whole world, $0.82 \%$ in Europe, and 0.43 in Italy [2, $3]$. It is associated with severe consequences for both individuals and society [4]. Heroin use is associated with somatic complications, including hepatitis $\mathrm{B}$, hepatitis $\mathrm{C}$, and immunodeficiency virus (HIV) infections, as well as pulmonary and cardiovascular complications [5], resulting in an increased risk of mortality [6]. Individuals with opioid use disorder also have a higher prevalence of psychiatric disorders, particularly depression, anxiety, and personality disorders [7]. Moreover, opioid use disorder results in an economic burden for society, in terms of medical expenses, social welfare, loss of productivity, and costs of criminal activities [8].

The main pharmacological approach in treating opioid dependence involves opioid agonist maintenance [4, 9]. It consists in the replacement of the illegal drug, which has a 2- to 3-h half-life, with a prescribed opioid, which has a longer half-life and a good $\mu$-receptor activity [10]. This approach aims to give relief from drug craving and withdrawal symptoms without providing patients with an intense high $[9,10]$. The medications most frequently used are methadone and buprenorphine [9], which have proven to be effective in reducing heroin use, maintaining prolonged periods of abstinence, increasing retention in drug treatment, and reducing the risk of overdose-related death $[4,11,12]$. Given their proven efficacy, these two drugs have been included by the World Health Organization in the Model List of Essential Medicines [4].

Charge-free heroin use disorder treatment in Italy follows two main approaches, i.e., harm reduction treatment (HRT) strategy $[13,14]$ in community lowthreshold facilities for drug addiction and opioid agonist treatment (OAT) in high-threshold facilities for opioid addiction, focusing on pharmacological maintenance according to the Dole and Nyswander strategy [9, 15-17]. Traditionally, physicians consider complete abstinence as the best and only treatment for substance use. However, in recent years this paradigm has been losing ground. The alternative treatment called HRT has been gaining stronger empirical support and wider practice, even if, as all evidence-based approaches [18], it is in need of further development. The rationale of HRT is that patients will continue to use illicit drugs to some degree, as in some of them it is just unavoidable, and rather than pushing them into an abstinence they will not immediately or fully accept, physicians will step into provide support that can make drug use less harmful. It has been demonstrated that methadone-based HRT, in which the use of illicit drugs is tolerated, is strongly related to decreased mortality from natural causes and from overdoses [19].
In HRT, doses and treatment duration are usually limited, regardless of clinical indication [20,21], suggesting the possible usefulness of increasing them [22-25]. Patients are allowed to negotiate dosage lowering, regardless of urinalyses results, and to have their medication tapered earlier than advisable on the basis of the scientific literature. A weakness of HRT is that physicians do not seem eager to work with patients who continue to use drugs, even if in a safer or more controlled manner, but without achieving a long-term withdrawal. A study carried out in Canada [26] found that only $56 \%$ of physicians working in addiction treatment facilities would be willing to provide long-term replacement therapy. OAT with methadone or buprenorphine has long been established as the gold standard in treating opioid use disorders, although not without fairly substantial financial and personal costs for patients taking part in this treatment [27]. OAT has been shown to reduce the effects of opioid withdrawal and cravings, increase retention in treatment, and reduce risk behaviors that lead to the transmission of HIV and viral hepatitis [28-31]. However, abstinence as a medium- and long-term goal is not always achieved and some patients continue to abuse heroin during treatment [32]. Moreover, they frequently abuse other non-opiate drugs, such as cocaine and cannabinoids $[8,33]$. Concurrent cocaine use is particularly challenging in clinical practice, as it is associated with poor prognosis both in terms of treatment drop-out and heavy concurrent use of heroin [33-37]. There is also an ongoing debate regarding the qualitative characteristics that define the optimal OAT intervention, namely the treatment threshold. "Treatment thresholds" are defined as barriers patients may face prior to and during treatment. There are increasing numbers of studies suggesting better treatment outcomes in low-threshold designs compared to high-threshold ones, due to accessibility so as to avoid waiting lists, use of personalized treatment options regarding medication choice and dose titration, and a treatment design that focuses on maintenance with emphasis on the retention of low-adherence patients [38]. In OAT four phases are envisaged [4, 9]: during the induction phase street heroin or other opioid drugs are substituted with an opioid agonist. During the stabilization phase physicians determine the appropriate agonist dose for long-term maintenance. The doses are gradually increased, reflecting the results of urinalyses, until they produce opioid blockade and patients become tolerant to street heroin. Once this requirement is fulfilled, patients are defined as "stabilized" and the dose at which this goal has been accomplished is referred to as the "stabilization dose". No upper limit for doses exists. However, a time limit exists: patients who cannot achieve stabilization within 1 year are transferred to the HRT approach. 
Patients are not allowed to raise or lower doses by themselves. Take-home doses, without limitations and for maximum a week, are allowed once full compliance with the rules of the program is reached. This is the maintenance phase. During the medically supervised withdrawal phase a slow reduction of the agonist dose is applied until patients are completely drug-free. Psychosocial support is usually provided [9], as it has been demonstrated that the association of pharmacotherapy and psychosocial interventions improves results at follow-up [13, 39].

Due to uncertainty regarding which treatment is more effective in the medium and long term, our aim was to compare the impact of HRT and OAT on patient outcome, as assessed through negativity for drugs on about 1 -year regularly performed urinalyses. We hypothesized that OAT patients would show better outcomes in terms of heroin, cocaine, and cannabinoids use than HRT ones during maintenance and supervised withdrawal phases. We did not expect to find a relationship between this better outcome and the agonist opioid dose taken by patients.

\section{Methods \\ Design of the study}

We conducted a retrospective and naturalistic study to compare urinalyses results of HRT and OAT patients for which at least four randomly sampled urinalyses per month were available for about 1 year, during which patients were undergoing methadone or buprenorphine maintenance; urinalyses focused on heroin, cocaine, cannabinoids, and their metabolites. OAT patients were monitored after having completed their induction and stabilization phase. Given that maintenance phase in OAT patients did not generally start before 6 months of treatment, monitoring of HRT patients did not start before 6 months of treatment.

\section{Sample}

We took into account a dataset of more than 1000 heroin-dependent patients, who had requested treatment during the period 1994-2015 at the Dual Diagnosis Unit of Santa Chiara University Hospital in Pisa, Italy, and at the Drug Addiction Service of Bolzano, Italy. All patients received a diagnosis of opioid dependence with physical dependence according to DSM III/III-R/IV/IV-R/5 criteria and gave their informed consent to the anonymous use of their clinical data for non-profit research.

Patients were selected if urinalyses for heroin, cocaine, and cannabinoids had been monitored for almost a year and collected randomly at least four times per month. As a result, 247 patients were included in the study: 189 HRT patients and 58 OAT patients.

\section{Instruments}

Information regarding patients' addiction history was obtained from the drug addiction history questionnaire (DAH-Q) [40]. As for toxicological urinalyses, urine specimens were tested for opioids, cocaine, cannabinoids, and their metabolites.

\section{Drug addiction history questionnaire (DAH-Q)}

The DAH-Q [40] is a multi-dimensional questionnaire that gathers addiction-related information and is administered by a psychiatrist. It comprises the following eight areas: (1) demographic data; (2) physical health (hepatic, vascular, and lymphatic pathology, gastrointestinal disorders, sexual disorders, dental pathology, HIV seropositivity); (3) mental health (awareness of illness, memory disorders, mood disorders, anxiety disorders, thought disorders, sensory perception disorders); (4) social adjustment and environmental factors (employment, family, sex, socialization and leisure time, legal problems); (5) substance use (alcohol, opiates, CNS depressants, CNS stimulants, hallucinogens, phencyclidine, cannabis, inhalants, polysubstance use); (6) substance use modalities (heroin intake, modality of use, stages of illness, nosography); (7) treatment history (previous and current treatments); (8) addiction history (age at first contact, age at onset of continuous use, dependence length, age at first treatment). Ten items are set up so as to elicit dichotomous answers (yes/no): (1) somatic comorbidities; (2) abnormal mental status; (3) work problems; (4) household problems; (5) sexual problems; (6) socialization and leisure time problems; (7) drug-related legal problems; (8) polysubstance abuse; (9) previous treatment; (10) combined treatments.

In the questionnaire, the modality of use is encoded according to Lahmeyer's classification [41] as follows: (1) stables; (2) junkies; (3) two worlders; (4) loners. "Stables" are opioid addicts who have adopted conventional values, hold legitimate jobs, are generally law-abiding, and do not associate with other addicts. "Junkies" are closely identified with an addict subculture, are not legitimately employed, and subsist on the proceeds of criminal activities. "Two worlders" engage in criminal activities and associate with other addicts, but are legitimately employed. "Loners" are not involved neither in the addict subculture, nor the conventional culture: they are usually unemployed and live on welfare benefits, rather than on the proceeds of criminal activities.

The questionnaire does not provide statistic or psychometric indexes that require reliability or validity testing; it serves only as standardized medical record that we use in the routinely clinical practice. 


\section{Toxicological urine analyses}

Urine samples for toxicological analyses were randomly collected monthly to allow the evaluation of the presence of opiates, cocaine, cannabinoids, and their metabolites. The enzyme-multiplied immune technique was used for this purpose.

\section{Data analysis}

We compared HRT and OAT patients for socio-demographic data, addiction history, urinalyses, and opioid medication doses. The variables that differed significantly between the two groups were included in separate logistic forward regression analyses, considering as a dependent variable whether one belonged to the OAT group or not. Statistical significance was set at $p<0.05$. All $p$ values were two-sided. Statistical analyses were carried out using the SPSS package 20.0.

\section{Results}

\section{Socio-demographic features}

In our study, 191 (77.3\%) patients were males and 56 (22.7 \%) females. Patients' mean age \pm standard deviation (SD) was $33.64 \pm 9.1$ years (age range $16-59$ years). Education length was less than 8 years in 169 (69.0\%) patients; 172 (70.8 \%) patients were single; 85 (34.4\%) patients were unemployed. Economic condition was adequate in 205 (83.0\%) patients, whereas 23 (9.3\%) received welfare benefit. Forty-eight (19.4\%) patients lived alone.

Table 1 shows the main socio-demographic differences between HRT and OAT patients.

\section{Clinical features}

OAT patients, more frequently than HRT ones, were affected by psychiatric and physical comorbidities and had been previously treated (Table 1 ). Their observation period was longer (Table 1). As regards addiction history, OAT patients showed a longer dependence duration than HRT ones. No difference was observed in terms of age of first heroin use, of continuous use, and of first treatment, as well as in terms of modalities of heroin use (Table 1).

\section{Urinalyses}

Table 2 shows the mean and SD of clean urinalyses of HRT and OAT patients according to the substitution medication type. At the multivariate level, there was a statistically significant interaction between the effects of clean urinalyses and treatment modality $(p=0.002)$. Differently, the interaction between the effects of clean urinalyses and substitution medication type was not statistically significant $(p=0.118)$. The interaction between treatment modality and substitution medication type was not statistically significant $(p=0.512)$ (Table 2$)$. Differences at the univariate level are reported in Table 2.
Table 3 shows that cocaine-clean urinalyses was the most discriminating characteristic of OAT patients (OR $7.47 \mathrm{E}+21)$.

\section{Substitution medication}

The mean methadone dose was lower in OAT than in HRT patients. No differences in buprenorphine doses were observed.

\section{Correlations between clean urinalyses and substitution medication doses}

Regarding HRT patients, significant correlations were found between methadone dose and heroin-clean urinalyses $(p=0.017)$. High dosages correlated with a low percentage of heroin-clean urinalyses. A high percentage of heroin-clean urines correlated with a high percentage of cocaine- $(p=0.000)$ and cannabinoids- $(p=0.000)$ clean urinalyses. Considering OAT patients, no significant correlations were found between methadone or buprenorphine dose and clean urinalyses. A high percentage of heroin-clean urines correlated with a high percentage of cocaine-clean $(p=0.009)$ urinalyses.

\section{Discussion}

Compared to HRT patients, OAT ones were older, more frequently females, more likely to live alone, and to have more workplace and justice issues. They had longer dependence duration, more severe addiction history, and received lower methadone doses. They were also observed for a significantly longer period. There was a higher proportion of heroin- and cocaine-clean urinalyses in OAT patients, with cocaine-clean urinalyses discriminating best between the two groups. Buprenorphine maintenance was more often associated with heroinclean urinalyses. The higher the methadone doses, the lower were the percentage of heroin-clean urinalyses in HRT patients (negative correlation).

Our results are inconsistent with those of the Cochrane review by Faggiano et al. [23] that found that higher methadone doses (60-100 $\mathrm{mg} /$ day) were more effective than lower ones (1-39 $\mathrm{mg} /$ day) in reducing heroin use during methadone maintenance treatment. However, in line with our findings, several studies [10, 42, 43] failed to demonstrate a clear association between high methadone doses on the one hand and reduction of heroin use or clinical stabilization on the other hand. More specifically, Blaney and Craig [42] found no significant differences regarding any outcome variable (illicit drug use, treatment retention, missed medication days) by methadone dose and concluded that researchers should pay more attention to the interpersonal aspects of methadone maintenance treatment. Moreover, Reimer et al. [10], using the opiate dosage adequacy scale (ODAS) in 
Table 1 Demographic and clinical differences between harm reduction treatment and opioid agonist treatment patients

\begin{tabular}{|c|c|c|c|c|}
\hline & $\begin{array}{l}\text { HRT strategy } \\
N=189\end{array}$ & $\begin{array}{l}\text { OAT strategy } \\
N=58\end{array}$ & T/chi & $p$ \\
\hline \multicolumn{5}{|l|}{ Demographics } \\
\hline Age, $M \pm s d$ & $30.41 \pm 6.3$ & $44.14 \pm 8.7$ & -11.09 & 0.000 \\
\hline Gender (females), N (\%) & $33(17.5)$ & $23(39.7)$ & 12.47 & 0.000 \\
\hline Education (low), N (\%) & $120(63.5)$ & $49(87.5)$ & 11.63 & 0.001 \\
\hline Single, $N(\%)$ & $131(70.1)$ & $41(73.2)$ & 0.20 & 0.648 \\
\hline Unemployed, $N(\%)$ & $66(35.1)$ & $19(32.8)$ & 4.77 & 0.189 \\
\hline Income (adequate), N (\%) & $151(79.9)$ & $54(93.1)$ & 5.48 & 0.019 \\
\hline Welfare benefit, $N(\%)$ & $3(1.6)$ & $20(34.5)$ & 56.87 & 0.000 \\
\hline Living alone, $N(\%)$ & $19(10.1)$ & $29(50.0)$ & 45.23 & 0.000 \\
\hline \multicolumn{5}{|l|}{ Clinical features at treatment entry } \\
\hline Age heroin first use, $M \pm s d$ & $18.64 \pm 4.1$ & $19.69 \pm 5.1$ & -1.59 & 0.112 \\
\hline Age of continuous use, $\mathrm{M} \pm \mathrm{sd}$ & $21.33 \pm 4.5$ & $23.02 \pm 6.0$ & -1.96 & 0.053 \\
\hline Dependence length (years), $M \pm s d$ & $7.30 \pm 5.7$ & $22.00 \pm 9.1$ & -11.60 & 0.000 \\
\hline Age first treatment, $M \pm s d$ & $24.72 \pm 4.9$ & $25.36 \pm 6.3$ & -0.75 & 0.477 \\
\hline Somatic complications, presence, $N(\%)$ & $130(68.8)$ & $51(89.5)$ & 9.64 & 0.002 \\
\hline Altered mental status, presence, $N(\%)$ & $139(73.5)$ & $55(98.2)$ & 15.95 & 0.000 \\
\hline Job concerns, presence, $N(\%)$ & $77(41.6)$ & $35(66.0)$ & 9.85 & 0.002 \\
\hline Household concerns, presence, $N(\%)$ & $57(30.5)$ & $33(57.9)$ & 14.10 & 0.000 \\
\hline Loving concerns, presence, $N(\%)$ & $64(33.9)$ & $38(66.7)$ & 19.41 & 0.000 \\
\hline Social-leisure concerns, presence, $N(\%)$ & $74(39.2)$ & $33(57.9)$ & 6.25 & 0.012 \\
\hline Legal problems, presence, $N(\%)$ & $56(29.6)$ & $36(62.1)$ & 19.98 & 0.000 \\
\hline Polyabuse, presence, $N(\%)$ & $77(40.7)$ & $16(28.6)$ & 2.71 & 0.099 \\
\hline Past treated, $N(\%)$ & $161(85.2)$ & $58(100.0)$ & 9.52 & 0.002 \\
\hline Combined treatments, $N(\%)$ & $164(86.8)$ & $54(94.7)$ & 2.75 & 0.097 \\
\hline Heroin intake, daily or more, $N(\%)$ & $113(59.8)$ & $41(70.7)$ & 2.24 & 0.134 \\
\hline Modality of use, unstable, $N(\%)$ & $58(30.7)$ & $16(28.1)$ & 0.14 & 0.706 \\
\hline Periodic self detoxifications, $N(\%)$ & $137(72.5)$ & $49(84.5)$ & 3.43 & 0.064 \\
\hline Stage 3 reached, $N(\%)$ & $147(77.8)$ & $46(79.3)$ & 0.06 & 0.805 \\
\hline Dual diagnosis, presence, $N(\%)$ & $108(57.1)$ & $32(55.2)$ & 0.07 & 0.791 \\
\hline Observational period (months), $\mathrm{M} \pm \mathrm{sd}$ & $13.34 \pm 3.0$ & $18.68 \pm 3.8$ & -9.69 & 0.000 \\
\hline \multirow[t]{2}{*}{ Substitution medications } & HRT strategy & OAT strategy & $z^{*}$ & $p$ \\
\hline & $N=102$ & $N=43$ & & \\
\hline \multirow[t]{2}{*}{ Methadone dose, $\mathrm{M} \pm$ sd } & $67.21 \pm 25.8$ & $53.12 \pm 25.9$ & -2.65 & 0.008 \\
\hline & $N=87$ & $N=15$ & & \\
\hline Buprenorphine dose, $M \pm s d$ & $7.29 \pm 4.2$ & $6.47 \pm 4.4$ & -0.94 & 0.343 \\
\hline
\end{tabular}

a sample of patients in opioid replacement treatment, found that as many as $40.6 \%$ suffered from an inadequate dosage, while $59.4 \%$ had an adequate dosage. The "inadequate" group tended to receive higher doses of methadone when compared to the "adequate" group (70.6 vs. $57.8 \mathrm{mg}$ ). Trafton et al. [43] suggest that clinicians should individualize methadone doses as long as outcomes are satisfactory: extremely low doses $(2 \mathrm{mg} /$ day $)$ may be effective in some patients, while extremely high doses (over $160 \mathrm{mg} /$ day) are required in other patients to reduce or stop heroin use. Furthermore, in our HRT patients we found a positive correlation between methadone doses and the percentage of urines positive for heroin metabolites. We can hypothesize that the patients who received the highest methadone doses in clinical practice were those with a severe addiction, thus more difficult to treat. On the other hand, no significant correlation was found between methadone dosage and heroin use among OAT patients.

In our sample, about $10 \%$ of urine toxicology tests were positive for cocaine, with significant differences between HRT and OAT patients. Similarly, other studies 
Table 2 Clean urinalyses percentage of harm reduction and agonist opioid treatment patients according to substitution medication used

\begin{tabular}{|c|c|c|c|c|}
\hline \multirow[t]{2}{*}{ Modality } & \multirow[t]{2}{*}{ Medication } & \multicolumn{3}{|c|}{ Clean urinalyses } \\
\hline & & Heroin & Cocaine & Cannabinoid \\
\hline \multirow[t]{3}{*}{ HRT } & Buprenorphine $(N=87)$ & $0.88 \pm 0.2$ & $0.91 \pm 0.2$ & $0.75 \pm 0.3$ \\
\hline & Methadone $(N=102)$ & $0.79 \pm 0.3$ & $0.86 \pm 0.2$ & $0.68 \pm 0.3$ \\
\hline & Total $(N=189)$ & $0.83 \pm 0.2$ & $0.88 \pm 0.2$ & $0.71 \pm 0.3$ \\
\hline \multirow[t]{3}{*}{ OAT } & Buprenorphine $(N=15)$ & $0.97 \pm 0.1$ & $0.97 \pm 0.1$ & $0.83 \pm 0.3$ \\
\hline & Methadone $(N=43)$ & $0.93 \pm 0.1$ & $0.97 \pm 0.1$ & $0.70 \pm 0.4$ \\
\hline & Total $(N=58)$ & $0.94 \pm 0.1$ & $0.97 \pm 0.1$ & $0.73 \pm 0.4$ \\
\hline \multirow[t]{3}{*}{ Total } & Buprenorphine $(N=102)$ & $0.89 \pm 0.2$ & $0.92 \pm 0.2$ & $0.76 \pm 0.3$ \\
\hline & Methadone $(N=145)$ & $0.83 \pm 0.2$ & $0.89 \pm 0.2$ & $0.68 \pm 0.3$ \\
\hline & Total $(N=247)$ & $0.86 \pm 0.2$ & $0.90 \pm 0.2$ & $0.72 \pm 0.3$ \\
\hline \multicolumn{5}{|c|}{ Between-subjects effects } \\
\hline \multirow[t]{3}{*}{ Modality } & Heroin urinalyses & \multicolumn{2}{|c|}{$F=11.05 ; d f=1 ; p=0.001$} & \\
\hline & Cocaine urinalyses & \multicolumn{2}{|c|}{$F=11.09 ; d f=1 ; p=0.001$} & \\
\hline & Cannabinoid urinalyses & \multicolumn{2}{|c|}{$F=0.86 ; d f=1 ; p=0.353$} & \\
\hline \multirow[t]{3}{*}{ Medication } & Heroin urinalyses & \multicolumn{2}{|c|}{$F=3.98 ; d f=1 ; p=0.047$} & \\
\hline & Cocaine urinalyses & \multicolumn{2}{|c|}{$F=1.19 ; d f=1 ; p=0.275$} & \\
\hline & Cannabinoid urinalyses & \multicolumn{2}{|c|}{$F=3.73 ; d f=1 ; p=0.055$} & \\
\hline \multirow[t]{3}{*}{ Modality*medication } & Heroin urinalyses & \multicolumn{2}{|c|}{$F=0.68 ; d f=1 ; p=0.409$} & \\
\hline & Cocaine urinalyses & \multicolumn{2}{|c|}{$F=1.13 ; d f=1 ; p=0.289$} & \\
\hline & Cannabinoid urinalyses & \multicolumn{2}{|c|}{$F=0.37 ; d f=1 ; p=0.542$} & \\
\hline
\end{tabular}

Multivariate test: modality effect: $F=5.24 ; d f=3 ; p=0.002$. Medication effect: $F=1.97 ; d f=3 ; p=0.118$. Modality*medication effect: $F=0.77 ; d f=3 ; p=0.512$

Table 3 Most discriminant characteristics of OAT patients

\begin{tabular}{llllll}
\hline Step & Predictors & $\boldsymbol{B}$ & Odds ratio & $\mathbf{9 5} \% \mathbf{C l}$ & $\boldsymbol{p}$ \\
\hline 1 & $\begin{array}{c}\text { Dependence } \\
\text { length }\end{array}$ & 0.17 & 1.19 & $1.08-1.30$ & 0.000 \\
2 & $\begin{array}{c}\text { Duration of } \\
\text { observation }\end{array}$ & 0.38 & 1.46 & $1.17-1.82$ & 0.001 \\
3 & $\begin{array}{c}\text { Clean cocaine } \\
\text { urinalyses }\end{array}$ & 29.64 & $7.47 \mathrm{E}+12$ & $\begin{array}{l}46,674.13- \\
1.20 \mathrm{E}+21\end{array}$ & 0.002 \\
\hline
\end{tabular}

Statistic: Chi square 99.33, df 3, $p=0.000$ correct classified $90.8 \%$

monitoring patients in opiate agonist treatment found cocaine-positive urines with toxicological values ranging between 4.3 and $13 \%[10,44]$.

Even though previous studies (Cochrane review, [23]) indicated that higher doses of methadone $(60-100 \mathrm{mg} /$ day) were more effective to reduce cocaine use in patients in opiate agonist treatment, we found no association between cocaine use and methadone dosage in both groups of patients.

Our findings are consistent with those of Epstein et al. [44], who compared patients randomly assigned to methadone doses of 70 and $100 \mathrm{mg} /$ day, respectively. They found that the percentage of urines negative for cocaine or for opiates and cocaine simultaneously did not differ by dose. Noteworthy, Baumeister et al. [45] found that patients in the low dose group had significantly fewer cocaine consumption days than patients in the currently recommended dose range $>60 \mathrm{mg} /$ day. Moreover, in line with previous studies [45-47], we found a positive association between heroin and cocaine use in HRT and OAT patients. Our findings suggest that methadone maintenance has an important role in restraining most of the cases of pre-existing concurrent cocaine abuse. The onset of cocaine abuse during a successful methadone maintenance program is quite unlikely and is best predicted by former analogous abuse [48]. Finally, we found neither a significant difference in buprenorphine doses among OAT and HRT patients nor any significant associations between doses of buprenorphine and heroin or cocaine use in both groups of patients. Buprenorphine seemed to confirm its role in clearing heroin urinalyses better than methadone [49].

Regarding the percentage of cannabis use, no significant differences were found between HRT and OAT patients. Similarly to Epstein and Preston [50] we found that cannabis use was not associated with cocaine or heroin use.

In our opinion, it is of clinical interest that OAT patients, following a correct induction and once the 
stabilization phase has taken place, can obtain lower percentages of heroin and cocaine in urinalyses compared to HRT patients, even if treated with significantly lower doses of methadone. In addition, lower use of cocaine during OAT is the most discriminating characteristics of this kind of treatment when compared to HRT strategy. It must be underlined that, at treatment entry, OAT patients had a higher prevalence of physical and psychiatric comorbidities, a longer dependence history, greater work problems, more unsatisfactory households, and more legal problems than HRT patients.

Furthermore, our results support the hypothesis of Willembring et al. [51] about the stability of the clinic's patient population: "Clinics with low turnover and a large number of patients that were stabilized on methadone years ago are likely to have lower average doses while still maintaining high concordance with dosing recommendations".

In a paper published in 1965 [52], Dole and Nyswander observed that 22 heroin addicts had been stabilized by oral methadone. The medication seemed to have two useful effects: relief of narcotic hunger and induction of sufficient tolerance to block the euphoric effect of an average illegal dose of heroin. With this medication and a comprehensive program of rehabilitation the patients showed marked improvement, pointing to a good efficacy of the OAT strategy.

The limitations of this study are due to its retrospective design and to the small cohort of patients who underwent the assessment. A study designed specifically to elucidate this issue should be carried out. Assessments of the same patient in different clinical presentations of the natural history of heroin dependence would have provided more accurate information.

\section{Conclusions}

Even patients with more severe substance use disorder and with multiple psychiatric, physical and social comorbidities, when treated with an appropriate long-term opioid agonist treatment and a multi-modal approach, could have a significant recover and reach satisfactory outcomes in term of substance abstinence.

\section{Authors' contributions}

$J V B, A G I M, A C$, and IM designed the study and wrote the protocol. VC, LS, $L R$ and SB managed the literature searches and analyses. IM undertook the statistical analysis, and all the authors discussed the results. JVB and IM wrote the first draft of the manuscript. DP participated in writing the revised form. All authors revised the last draft. All the authors contributed to manuscript. All authors read and approved the final manuscript.

\section{Author details}

${ }^{1}$ Department of Psychiatry of Bolzano, Bolzano, Italy. ${ }^{2}$ Vincent P. Dole Dual Diagnosis Unit, Department of Neurosciences, Santa Chiara University Hospital, University of Pisa, Via Roma, 6756100 Pisa, Italy. ${ }^{3}$ AU-CNS-Association for the Application of Neuroscientific Knowledge to Social Aims, Pietrasanta, Italy. ${ }^{4} \mathrm{G}$ De Lisio Institute of Behavioural Sciences, Pisa, Italy.

\section{Acknowledgements}

The authors thank Molteni Pharmaceutical for providing funds for the Open Access publication. Molteni Pharmaceutical did not play a role in study design; in the collection, analysis and interpretation of data; in the writing of the report; and in the decision to submit the paper for publication.

\section{Competing interests}

The authors declare that they have no competing interests. IM served as Board Member for Indivior, Molteni, and Lundbeck.

Received: 13 October 2015 Accepted: 4 August 2016

Published online: 25 November 2016

References

1. McLellan AT, Lewis DC, O'Brien CP, Kleber HD. Drug dependence, a chronic medical illness: implications for treatment, insurance, and outcomes evaluation. JAMA. 2000;284(13):1689-95.

2. UNODC. World drug report 2014. 2014. www.unodcorg/unodc/ indexhtml?ref=menutop. Accessed 28 July 2010.

3. European Monitoring Centre for Drugs and Drug Addiction (EMCDDA) http://www.emcdda.europa.eu/countries/italy. Accessed 3 Apr 2010.

4. WHO. Guidelines for the psychosocially assisted pharmacological treatment of opioid dependence. 2009. www.who.int. Accessed 28 May 2010.

5. Reimer J, Verthein U, Karow A, Schafer I, Naber D, Haasen C. Physical and mental health in severe opioid-dependent patients within a randomized controlled maintenance treatment trial. Addiction. 2011;106(9):1647-55.

6. Degenhardt L, Bucello C, Mathers B, Briegleb C, Ali H, Hickman M, McLaren J. Mortality among regular or dependent users of heroin and other opioids: a systematic review and meta-analysis of cohort studies. Addiction. 2011;106(1):32-51.

7. Callaly T, Trauer T, Munro L, Whelan G. Prevalence of psychiatric disorder in a methadone maintenance population. Aust N Z J Psychiatry. 2001;35(5):601-5.

8. Scavone JL, Sterling RC, Van Bockstaele EJ. Cannabinoid and opioid interactions: implications for opiate dependence and withdrawal. Neuroscience. 2013;248:637-54.

9. Maremmani I, Pacini M, Pani PP, on behalf of the 'Basics on Addiction Group.' Basics on addiction: a training package for medical practitioners or psychiatrists who treat opioid dependence. Heroin Addict Relat Clin Probl. 2011;13(2):5-40. http://www.heroinaddictionrelatedclinicalproblems.org/harcp-archives.php?year $=2011$.

10. Reimer J, Boniakowski E, Bachner C, Weber B, Tietje W, Verthein U, Walcher S. When higher doses in opioid replacement treatment are still inadequate-association to multidimensional illness severity: a cohort study. Subst Abuse Treat Prev Policy. 2014;9:13.

11. Mattick RP, Breen C, Kimber J, Davoli M. Methadone maintenance therapy versus no opioid replacement therapy for opioid dependence. Cochrane Database Syst Rev. 2003(2):CD002209. http://www.ncbi.nlm.nih.gov/ pubmed/12804430.

12. Schottenfeld RS, Chawarski MC, Mazlan M. Maintenance treatment with buprenorphine and naltrexone for heroin dependence in Malaysia: a randomised, double-blind, placebo-controlled trial. Lancet. 2008;371(9631):2192-200.

13. Maremmani I, Pacini M, Lubrano S, Giuntoli G, Lovrecic M. Harm reduction and specific treatments for heroin addiction. Different approaches or levels of intervention? An illness-centred perspective. Heroin Addict Relat Clin Probl. 2002;4(3):5-11. http://www.heroinaddictionrelatedclinicalproblems.org/harcp-archives.php?year $=2002$.

14. Wells B. Methadone maintenance treatment: harm reduction or rehabilitation? Addiction. 1994;89:806.

15. Dole VP, Nyswander ME, Kreek MJ. Narcotic blockade. Arch Intern Med. 1966;118:304-9.

16. Dole VP, Nyswander ME. Heroin addiction. A metabolic disease. Arch Intern Med. 1967;120:19-24.

17. Dole VP. Methadone maintenance. Comes of age. In: Tagliamonte A, Maremmani I, editors. Drug addiction and related clinical problems. New York: Springer-Verlag; 1995. p. 45-9. 
18. Lenton S, Single E. The definition of harm reduction. Drug Alcohol Rev. 1998;2:213-9.

19. Langendam MW, Van Brussel GH, Coutinho RA, Van Ameijden EJ. The impact of harm-reduction-based methadone treatment on mortality among heroin users. Am J Public Health. 2001;91(5):774-80.

20. Schifano F, Bargagli AM, Belleudi V, Amato L, Davoli M, Diecidue R, Versino E, Vigna-Taglianti F, Faggiano F, Perucci CA. Methadone treatment in clinical practice in Italy: need for improvement. Eur Addict Res. 2006;12(3):121-7.

21. Salamina G, Diecidue R, Vigna-Taglianti F, Jarre P, Schifano P, Bargagli AM, Davoli M, Amato L, Perucci CA, Faggiano F. Effectiveness of therapies for heroin addiction in retaining patients in treatment: results from the VEdeTTE study. Subst Use Misuse. 2010;45(12):2076-92.

22. D'Ippoliti D, Davoli M, Perucci CA, Pasqualini F, Bargagli AM. Retention in treatment of heroin users in Italy: the role of treatment type and of methadone maintenance dosage. Drug Alcohol Depend. 1998;52(2):167-71.

23. Faggiano F, Vigna-Taglianti F, Versino E, Lemma P. Methadone maintenance at different dosages for opioid dependence. Cochrane Database Syst Rev 2003;3:CD002208. http://www.ncbi.nlm.nih.gov/ pubmed/12917925.

24. Brady TM, Salvucci S, Sverdlov LS, Male A, Kyeyune H, Sikali E, DeSale S, Yu P. Methadone dosage and retention: an examination of the $60 \mathrm{mg} /$ day threshold. J Addict Dis. 2005;24(3):23-47.

25. Pollack HA, D'Aunno T. Dosage patterns in methadone treatment: results from a national survey, 1988-2005. Health Serv Res. 2008;43(6):2143-63.

26. Dooley J, Asbridge M, Fraser J, Kirkland S. Physicians' attitudes towards office-based delivery of methadone maintenance therapy: results from a cross-sectional survey of nova scotia primary-care physicians. Harm Reduct J. 2012;9:20

27. Lenne M, Lintzeris N, Breen C, Harris S, Hawken L, Mattick R, Ritter A. Withdrawal from methadone maintenance treatment: prognosis and participant perspectives. Aust N Z J Public Health. 2001;25(2):121-5.

28. Dole VP, Robinson JW, Orraca J, Towns E, Searcy P, Caine E. Methadone treatment of randomly selected criminal addicts. N Engl J Med. 1969;280(25):1372-5.

29. Gowing LR, Farrell M, Bornemann R, Sullivan LE, Ali RL. Brief report: methadone treatment of injecting opioid users for prevention of HIV infection. J Gen Intern Med. 2006;21 (2):193-5.

30. Gronbladh L, Ohlund LS, Gunne LM. Mortality in heroin addiction: impact of methadone treatment. Acta Psychiatr Scand. 1990;82(3):223-7.

31. Newman RG, Whitehill WB. Double-blind comparison of methadone and placebo maintenance treatments of narcotic addicts in Hong Kong Lancet. 1979;2(8141):485-8.

32. McLellan AT, Arndt IO, Metzger DS, Woody GE, O'Brien CP. The effects of psychosocial services in substance abuse treatment. JAMA. 1993:269(15):1953-9.

33. Kennedy AP, Phillips KA, Epstein DH, Reamer DA, Schmittner J, Preston $\mathrm{KL}$. A randomized investigation of methadone doses at or over $100 \mathrm{mg} /$ day, combined with contingency management. Drug Alcohol Depend. 2013;130(1-3):77-84.

34. Dale-Perera A, Goulão J, Stöver H. Quality of care provided to patients receiving opioid maintenance treatment in Europe: results from the EQUATOR analysis. Heroin Addict Relat Clin Probl. 2012;14(4):23-38.

35. Fischer G, Stöver H. Assessing the current state of opioid-dependence treatment across Europe: methodology of the European quality audit of opioid treatment (EQUATOR) project. Heroin Addict Relat Clin Probl. 2012;14(3):5-70.
36. Maremmani I. Foreword-EQUATOR publication series. Heroin Addict Relat Clin Probl. 2012;14(4):5-6.

37. Stöver H. Assessing the current state of public-health-related outcomes in opioid dependence across Europe: data from the EQUATOR analysis. Heroin Addict Relat Clin Probl. 2012;14(4):51-64.

38. Kourounis G, Richards BD, Kyprianou E, Symeonidou E, Malliori MM, Samartzis L. Opioid substitution therapy: lowering the treatment thresholds. Drug Alcohol Depend. 2016;161:1-8.

39. Amato L, Minozzi S, Davoli M, Vecchi S. Psychosocial and pharmacological treatments versus pharmacological treatments for opioid detoxification. Cochrane Database Syst Rev. 2011;9:CD005031. http://www.ncbi.nlm.nih. gov/pubmed/21901695.

40. Maremmani I, Castrogiovanni P. DAH-Q: drug addiction questionnaire. Pisa: University Press; 1989.

41. Lahmeyer HW, Channon RA, Schlemmer FJ. Psychoactive substance abuse. In: Flaherty JA, Channon RA, Devis JM, editors. Psychiatry diagnosis and terapy. San Mateo: Appleton \& Lange; 1988. p. 182-99.

42. Blaney T, Craig RJ. Methadone maintenance. Does dose determine differences in outcome? J Subst Abuse Treat. 1999;16(3):221-8.

43. Trafton JA, Minkel J, Humphreys K. Determining effective methadone doses for individual opioid-dependent patients. PLos Med. 2006;3(3):e80.

44. Epstein DH, Schmittner J, Umbricht A, Schroeder JR, Moolchan ET, Preston KL. Promoting abstinence from cocaine and heroin with a methadone dose increase and a novel contingency. Drug Alcohol Depend. 2009;101(1-2):92-100.

45. Baumeister M, Vogel M, Dursteler-MacFarland KM, Gerhard U, Strasser J, Walter M, Wiesbeck GA, Petitjean SA. Association between methadone dose and concomitant cocaine use in methadone maintenance treatment: a register-based study. Subst Abuse Treat Prev Policy. 2014;9:46.

46. Hartel DM, Schoenbaum EE, Selwyn PA, Kline J, Davenny K, Klein RS, Friedland GH. Heroin use during methadone maintenance treatment: the importance of methadone dose and cocaine use. Am J Public Health. 1995;85(1):83-8.

47. Kamal F, Flavin S, Campbell F, Behan C, Fagan J, Smyth R. Factors affecting the outcome of methadone maintenance treatment in opiate dependence. Ir Med J. 2007;100(3):393-7.

48. Maremmani I, Pani PP, Mellini A, Pacini M, Marini G, Lovrecic M, Perugi G, Shinderman M. Alcohol and cocaine use and abuse among opioid addicts engaged in a methadone maintenance treatment program. J Addict Dis. 2007;26(1):61-70.

49. Gerra G, Borella F, Zaimovic A, Moi G, Bussandri M, Bubici C, Bertacca S. Buprenorphine versus methadone for opioid dependence: predictor variables for treatment outcome. Drug Alcohol Depend. 2004;75(1):37-45.

50. Epstein DH, Preston KL. Does cannabis use predict poor outcome for heroin-dependent patients on maintenance treatment? Past findings and more evidence against. Addiction. 2003;98(3):269-79.

51. Willenbring ML, Hagedorn HJ, Postier AC, Kenny M. Variations in evidence-based clinical practices in nine United States Veterans Administration opioid agonist therapy clinics. Drug Alcohol Depend. 2004;75(1):97-106.

52. Dole VP, Nyswander M. A medical treatment for diacetylmorphine (heroin) addiction. A clinical trial with methadone hydrochloride. JAMA. 1965;193:646-50. 